\title{
Ethics and Professionalism in Education as Tools for Social Reconstruction and Development
}

\author{
Samuel Asuquo Ekanem, Ph.D ,Llb (Hons), BI \\ Department of Educational Foundations and Administration, Faculty of Education \\ Cross River University of Technology, Calabar, Nigeria \\ Ekeng Nyong Ekefre, Ph.D \\ Department of Educational Foundations and Administration, Faculty of Education \\ Cross River University of Technology, Calabar, Nigeria
}

Doi:10.5901/mjss.2013.v4n14p15

\section{Abstract}

Education plays a vital role in the development of every country. A country is a living organism with several parts that need to be developed. As a complex organism, the development of each of its diverse parts requires some level of specialized knowledge. It is this complexity and organic nature of our modern society that has given birth to the various areas of knowledge with diverse aspects of specialization. It is therefore the complexity of human nature with its multiplicity of needs that has created complexity of modern civil society. Civil society is dynamic and develops in tandem with the diversities of human needs. Nothing ever emerges in the society without the focus or aim to satisfy the need of an aspect of human nature. So, every society with all its complexity is a reflection of human nature, with its diverse needs. It follows then that human nature is the basic foundation of our modern world or civil society. This also reflects the foundation of human knowledge in all spheres. Every aspect of knowledge is intrinsically linked with man and is designed to cater for the various needs of his complex nature. Education is therefore founded on human nature. The development and reconstruction of any society or country is therefore anchored on the process of catering for the diverse needs of man's complex nature. Society, education and morality have the same foundation, and that is human nature. Society cannot be separated from morality or education. Hence, in this paper, effort was made to establish the fact that ethics and professionalism in education are the basic tools that can bring about and inspire development and social reconstruction. The paper asserts that education is a conditio-sine-quanon for the development of any country and that this can only be achieved with ethical values and professional best practices. The paper posits that development and social reconstruction can only take place in a society where every aspect of human knowledge has an inbuilt ethical mechanism and professional standard.

\section{Introduction}

Education is an instrument par excellence for national development in all human societies both ancient and modern. It remains the best and basic means of transmitting and perpetuating culture for general development and technological advancement. Education is the only man's basic tool for discovering his nature; evaluate himself; domesticate and control his environment; create a social network and exchanges that can improve the society. The aim of education should be to produce men that pass both culture and expert knowledge in some special direction. This expert knowledge provides men/women the ground to start from, and their culture will lead them as deep as philosophy and as high as art.

The implication of this is that education is a complex combination of the totality of human nature with a focus on reflective newness or ideas for transformation. It is through education that man can preserve, improve and secure himself and the society. This makes education a development-driven human activity. As a development-centred activity, education becomes a multi-dimensional concept with man as its focus. The reason for this is that man possesses the rational and cognitive powers or abilities to interpret, analyse and utilize the products of his education for his benefit and that of his society.

The fundamental questions from this therefore are: to what extent has Nigeria as a country been able to utilize education or the products of education for her benefit? What is the place of education in the developmental agenda of the country? Do Nigerian leaders see education as a necessary tool for development?

A critical and an objective response to these questions will show that there are fundamental problems confronting our education and the educational system. These problems include lack of ethics and professionalism. It is the lack of 
these basic tools and tenets or foundation of education that has brought about the decay in our educational system. The absence of this foundation has made education not to be of any value in Nigeria. These have created the monsters we now have in our society, which include poverty, armed robbery, terrorism, cultism, political thuggery among other socioeconomic and political malaise that now confront Nigeria.

As a result of these problems, the development of Nigeria as a nation state has been hampered. Indeed, Nigeria is ranked the $13^{\text {th }}$ poorest nation in Africa. This ranking is despite the enormous natural resources of the nation. So, what then is the problem of Nigeria?

Though a lot of people have identified leadership or political leadership as the major problem of Nigeria's underdevelopment, this paper strongly differs in this direction. This paper identifies lack of ethics and professionalism in the field of education as the fundamental problem of the country's development. It therefore strongly advocates the establishment of ethical standard and professional practices as a means to bring about social reconstruction and development in Nigeria.

\section{Education and development}

Education plays a pivotal role in the development of a country. This is because as Omoregbe (2000) puts it, a country is a "living organism" with several parts, and each of these require a developmental effort geared towards it development. As a "complex organism, the development of the several aspects require specialized kind of knowledge and a certain degree of expertise in the relevant field of knowledge.

It is clear that the complex and organic nature of our modern society is what have brought about the different branches of knowledge with the multiple spheres of specialization. This can be seen in the diverse fields such as medicine, law, engineering, architecture, technology, science, economics, banking and finance, mathematics, philosophy of education, teacher education, administration, guidance and counseling, among others. All these are specialized kinds of knowledge that seek and strive to satisfy or provide for the complexity of our modern society. This societal complexity tallies with the platonic notion of society, being man - writ - large. It follows then that every aspect of our modern world or society develops intrinsically in response to the multiple needs of human nature. So, every aspect of the society is a natural response to an aspect of the requirement or needs of man's nature, and it is designed or aimed at taking care of it. The emergence of any or everything is directed or targeted at catering for the need of a specific or particular aspect of human nature. This makes education to be human centred. This is because, it is only the human person that can apply education for his own benefit and that of his society. This assertion is aptly captured by Booth and Gregory (1988) when they argued that "Education is the acquisition of the art of the utilization of knowledge." This has its root in Alfred North Whitehead's "The aim of education" written in 1929.

From the above analysis, it is discovered that the society with all its complexity is like a mirror that reflects human nature, with its multiple requirements. It is on the basis of this that Omoregbe (2000) opines that "human nature is the foundation of civil society", and that it is also the basic foundation of human knowledge in every aspect or spheres. This clearly indicates the relationship or the correlates between every branch of knowledge and man, showing the intention to cater for the aspects of the needs of man's complex nature. This provides the pillar for Omoregbe's argument that "All the branches of knowledge, with their multiple areas of specialization arose as answers to some questions posed by some aspects of human nature or as solutions to some of its problems."

It can rightly be deduced from this that human nature is the foundation upon which education is laid. It also follows that the aim of education is to cater for the various aspects of human nature. The development of a society or a country is therefore nothing but a designed process of catering for various needs of man's diverse and complex nature. So, when a country is said to have developed, it implies that such a country or society has made reasonable progress in the designed process that caters for the multiple needs of man as required by his complex nature (Omoregbe, 2000).

To effectively and adequately cater for the needs of human nature demands insightful and thorough knowledge of these needs and effectively these can be taken care of. This shows that professionalism and a high degree of expertise of the diverse needs and complex nature of man is required in the form of acquisition of knowledge. This knowledge can only be acquired or imparted through formal education, hence, education is a necessary requirement for the development of any society. Omoregbe totally agrees with this assertion when he states that "...education is a conditio-sine-qua-non for the development of any country." Indeed, the different aspects of the needs of human nature in our modern world or society and the best way to take care or cater for these needs demand specialized studies in the different fields of knowledge.

From this, the education of the citizenry in the different fields of knowledge with the diverse aspects of 
specialization is indisputably the anchor point and the foundation for the development and reconstruction of the society. No society or country can develop without properly trained or qualified experts and specialist in the various fields of studies or learning by the citizens. Where there is the lack of these experts or specialists, such a society is bound to remain dependent and underdeveloped. Every country or society needs the right person for the right job for such a country or society to develop.

Having the wrong person for the right job has been the major hindrance for the developmental strides of Nigeria. The issue of being a square peg in a round hole has been a clog in the country's wheel of development. This is because as Oshita (2009) puts it:

\begin{abstract}
Development is a multi-dimensional concept and it involves physical and mental aspects. In other words, development has structural and super-structural counterparts. The former refers to the growth of ideas, cultural, philosophical, literary, religious, political etc. National development refers to the sum total of the results of the functional relationship between manual and intellectual labour of the nation in the struggle for self-sustenance. It involves everything that is done within a nation with a view to uplifting the standard of men and materials.
\end{abstract}

The implication of the above is that education is the bedrock of development of any society. It is the basis and an effective mechanism of social reconstruction. However, for education to meet its social goal of development and social reconstruction, it must be anchored on a philosophy. The importance of a philosophy of education in Nigeria can be seen in the work of Oshita (2008) captioned "Philosophy of Education and National Development" when he writes:

\begin{abstract}
... in the era of transition up to the present day Nigeria, as education has to expand to meet the social needs of the new environment, there grew with it a need for social philosophy. This expresses itself in a common pattern of basic beliefs to form a moral rationale capable of fusing the diverse aims and beliefs of the different elements within the society into a common design. Such a design would then form a part of significance and articulation for the common welfare. What this means is the articulation of utility of education in the enhancement of attitudes and beliefs that would lend sanctions to social philosophy.
\end{abstract}

What can be gleaned from this is that philosophy helps to highlight the values discoverable in education. The attainment of this is through its ability to articulate the utility of education and relevance of education in reconstructing the society towards the standard of ethics and character moulding. This is better articulated by Ukeje (1966) when he alludes that; "... if philosophy expresses the beliefs of a people's culture, education helps to carry them out and, in so doing, builds additional habits and skills useful to the expression".

The concept of such a social philosophy of education follows the definite reference to the needs and issues of the time and must necessarily capture and reflect the hope and aspiration of the era or age. This confirms the fact that the social importance of education can best be achieved with a social philosophy of education. It is on the basis of this that Ekanem (2005) proposed "Essencism" as a philosophy of education for Nigeria. Essencism as a philosophy emphasizes the dualistic nature of man, which are the physical and spiritual. It also attempts to merge the super and super-structure aspects of development as championed by Oshita.

\title{
3. Ethics and Education
}

It has been established that man's complex nature is the foundation of knowledge, education and society. Also, man's nature as a rational and social being is the foundation of morality. Man, according to Omoregbe (2000), is a moral being by nature; this equally explains man's nature as a rational and social being. The implication of this is that morality as a concept has its root traceable to the rational and social nature of man. Without the rational and the social aspects of man, there would be no such thing as morality.

From this analysis, the discovery is that society (be it civil or modern), education and morality have the same foundation that is established on human nature. These three are centred on human nature and cannot therefore be separated from it. These three concepts or things are interwoven and are involved in an eternal wedlock where separation is impossible, and therefore, cannot be contemplated. This can be seen in the fact that society (which is manwrit-large or which is made of men) cannot be separated from morality or from education. This inseparability is based on the fact that it is only man that can justify his action as being right or wrong. Also, it is only man that possesses the rational and cognitive power to utilize his education positively or negatively. The triangle that exists here has man at each point. As a result of this, education cannot be separated from morality or from society. Again, any education that lacks morality, according to Omoregbe, is "incomplete and useless." He argued that such education is harmful both to the 
individual that acquires it and the society that he lives.

For education to achieve its social objective of catering for certain aspects of human needs in our country, it must according to Omoregbe, be imbued with morality in a very huge degree, otherwise it would do more harm than good to the society". Jean-Jacques Rousseau in his famous essay on the benefit of art and science to mankind argues that "since learned men began to appear among us, good men have disappeared". The implication of Rousseau's assertion is that the education of these learned men lacks morality. Due to the barrenness of morality in their education, those learned men could not contribute positively to the development of the society. Any education devoid of morality cannot be beneficial to the society or mankind since it cannot fulfill the purpose of catering for the needs of human nature. This situation prompted Agulana (2009) to opines that 'science gives us information about the world, ethics provides us with rules and standards for changing the world to fit our requirements.

A cursory look at this analysis reveals that education without morality is dangerous to man and the society. This therefore brings us to the dangerous situation in Nigeria. Our education has been devoid of morality, hence, the system tends to produce more corrupt leaders, cultists, rapists, armed robbers and men and women of easy virtues. This lack of morality has been the reason for the several socio-economic and political woes that confront Nigeria as a country. The lack of morality in our education totally removes the Socratic dictum of "unexamined life is not worth living" from our social and national life. This ethical notion that is concerned with the evaluation of human conduct is urgently needed in our education if Nigeria is to make any meaningful progress as a nation. The crises in the educational sector and our institutions of learning confirm this lack of morality in our education.

We can see the obstacles posed by the so called "educated people" in Nigeria. Since the political leaders did not have the kind of education that has morality, their style of governance is reflective of this lack of morality. This high incidence of corruption in the Nigerian society today is a clear testament to the moral decadence in the country. The political leaders are busy diverting funds meant for education into private foreign accounts and refusing to pay teachers and lecturers appropriate salary because these leaders have no sense of morality. This is the tragedy of developing countries that have refused to take morality among the citizenry very seriously. Moral education must be a necessary component of formal education, and this must be given top priority if the country is to develop. Morality must be given primacy in the educational system of Nigeria if the country is to develop and free herself from all the encumbrances currently inhibiting the development of the country in all spheres. Indeed, morality is an integral part of education and development. To Ozumba (2010) therefore, education "has to do with any instrumentation and process of enhancing knowledge, creating awareness, ensuring the propagation of positive values, for the general purpose of empowering the citizens to effectively perform their roles and function as change agents in the society.

It is from this standpoint that Ozumba (2010) sees education as being all about knowing the appropriate values and looking for means of "inculcating them or transmitting them to the citizens. It also has to do with bringing out latent qualities for the benefit of the citizenry. Education is all about learning to acquire knowledge, learning to act, learning to lives with others and learning for life".

\section{Ethics and Development}

Morality plays a vital role in the development of any nation. This is due to the fact that the most essential aspect of the development of a country is basically the development of the platonic notion that society is a reflection of the kind of people that make up the society. So, in a country where there is a high rate of corruption, it simply shows that there are many corrupt people living in such a society. Nigeria is said to be a corrupt society, and this implies that many Nigerians are corrupt. This has manifested in the corrupt practices of the political leaders. Recently, the anti-graft agency, the Economic and Financial Crime Commission (EFCC), declared a former governor of Gombe State wanted for misappropriation of public funds. Also, three other former governors of Ogun, Oyo and Nassarawa States have been arrested and will appear in court for graft related offences. The present senate probe of the federal government privatization exercise of public enterprises has shown how endemic corruption has become in Nigeria. All these point to the fact that there is something very fundamental that is missing in the Nigerian system. What is this missing element that has stalled the nation's development?

The simplest answer to this is morality. It is because Nigerian leaders do not have a sense of morality that is why public funds are being diverted on a daily basis to private pockets and foreign bank accounts. How can one explain the recent World Bank Report that a former military president stole 4.9 trillion naira (Channels Television, 2011). A person or a military president with a sense of morality cannot be this callous as to steal or divert our commonwealth to personal one. This is what informed Omoregbe to argue that the moral development of the citizenry is the most important aspect 
of the development of any country. This is anchored on the fact that there are other aspects of development, so as a country as a "living organism with many parts," there is need to develop all aspects of the country for there to be development. Where any part remains underdeveloped, the entire system or country will be affected. Each aspect has a distinct contribution to make towards the growth and wellbeing of the entire system, country or organism. Though each aspect of the organism is important but there are not of equal importance, hence, Omoregbe (2000) opines that "... some parts are of primary importance while others are of secondary importance. Those of secondary importance are subordinate to, and directed towards, those of primary importance through which they make their contributions to the whole organism. Consequently, the value of the secondary part is instrumental".

Furthermore, Omoregbe sees the primary aspects as corresponding to the human dimension while the secondary aspects are identified as the infra-human dimension. The latter can be said to include the land, roads, machines, natural resources, buildings, among others. All these are of essence or importance to a country and must be developed, but they are of secondary importance. Of primary importance is the human dimension. The implication of this is that the development of a country is primarily the development of the human persons, who are the citizens of such a country. Since the development of the citizenry is of primary important, it follows that the most vital aspect in the development of the human person is the moral development of the people. Moral maturity according to Omoregbe signifies the development of the human person, and this is the most important aspects of national development. It is therefore a "conditio-sine-qua-non" for national development. There cannot be development in a country where the citizens are morally underdeveloped and immature. This indeed, is the problem with our country, where the citizens especially the political class are morally bankrupt. The moral development of Nigerians must necessarily precede other aspects of development of the country which could be hampered by the immorality of the citizens.

The immorality of Nigerians is the greatest and the most formidable obstacle to the development of Nigeria. This also applies to every other country or society. For how can there be development in a country where public funds meant for developmental projects and education are diverted into private bank accounts? How can the economy of such a country develop? The economy of a country cannot develop where the citizens lack a sense of duty, a sense of patriotism (as can be seen in the failure of the national team to qualify for the 2012 cup of nations), a sense of moral responsibility and social accountability. How can there be development in Nigeria where bribery and corruption have broken down law and order? We cannot expect development in a country where the law enforcement and security agencies like the Police, Army, Navy, Customs and Immigration officials can easily be bribed by criminals. What kind of development do we expect in Nigeria where government officials defraud the country of billion of naira? Nigeria will remain underdeveloped because of the selfish interest of the citizens to enrich themselves.

The impact of this can be seen in Thomas Hobbes' Leviathan where he describes a society that is dominated by self-interest, with no sense of morality as "the state of nature" and there was neither development nor progress in that society. Life there was "nasty, brutish and short". This happens because there was no morality. The Hobbesian state of nature typically demonstrates the fact that morality is indispensable for social progress or development. It portrays the fact that civilization, social transformation and development can only occur where morality is enforceable by the citizenry. So, for Nigeria to progress, the country must be ready to enforce morality.

\section{The Importance of Ethics and Professionalism in Education}

From our analysis, it is evident that morality and education are inseparable. This is because man by nature is a moral and rational being. Man is also a social being. These make society, education and morality to be the foundation of human nature. As a social being therefore, the education and morality of man is to equip man with the necessary tools to be able to apply these for his own benefit and that of his society. This therefore forms the bedrock of our nation's objectives where the National Policy on Education stipulates the promotion of enabling attitudes that include:

- Faith in the power of human knowledge

- Respect for the worth and dignity of the individual

- Faith in man's ability to make rational decisions

- Moral and spiritual values of interpersonal and human relations.

- Shared responsibility for the common good of society.

- Promotion of emotional, physical and psychological health of all children.

These time-tested values of education enable the citizens to identify committedly with the rational aspirations and ideals of the society. However, these can only be effectively translated into action that can bring about social development where morality is implanted in the educational process. This is because without morality, education 
becomes a dangerous weapon of social domination. It is the lack of morality in education that makes Brown (2010) to argue that a person becomes more dangerous with more education where such education is devoid of morality. This is because education provides the human person the cognitive power to manipulate social variables and conditions to his own advantage.

For as Oshita (2009) asserts, education "exposes man to the array of contending opinions about things, but philosophy of education teaches us to maintain open and critical mind in the midst of a diversity of ideas." What can be inferred here is that education provides man diverse manipulative techniques to sway things to his favour. But philosophy of education that involves ethical principles or tools helps to regulate or check the social danger posed by education without morality. For instance, a lawyer who is vast and knowledgeable in law can use this to his own advantage though his action could be detrimental to the society. Here, the suspension of the president of the Court of Appeal, Justice Ayo Salami by the National Judicial Council is a clear testimony to education without morality. What the National Judicial Council (NJC) did was against the principle of natural justice and at variance with the 1999 Constitution of Nigeria. But the NJC was able to utilize its knowledge of the law to use the term "suspension."

Again, where morality is enforced, societal interest is always considered. But in the Salami's Saga, we see that the NJC was effectively manipulated by the Chief Judge of Nigeria who was at the verge of retiring. He used the NJC to achieve his personal vendetta. It is also this lack of morality in our education that will make a medical doctor not to attend to a patient in an emergency where certain amount of money is not deposited. The same medical doctor will carry out an abortion in his clinic once he is paid some amount. This will also make an engineer to use a sub-standard material in construction. The engineer knows the technical implication of his actions but because morality is not imbued in his engineering training, he could breach the technical standard requirement.

Professionalism in education is very necessary. This is because, it is only through professionalism that the appreciation of the structure of ideas that actually culture the mind can be achieved. Without professionalism, there cannot be specialization and expertise in education, hence Whitehead (1929) says:

The appreciation of the structure of ideas is the side of a cultured mind which can grow under the influence of a special study. I mean that eye for the white chessboard, for the bearing of one set of ideas on another. Nothing but a special study can give appreciation for the exact formulation of general ideas, for their relations when formulated, for their service in the comprehension of life. A mind so disciplined should be both more abstract and more concrete. It has been trained in the comprehension of abstract thought and in the analysis of fact.

Here, Whitehead was talking about professionalism and morality. This is because it is professionalism that creates style in art, style in literature, style in science, style in logic, and style in practical execution, from which aesthetic qualities are brought about or attained. It is professionalism that makes the utility of education possible, but this must be imbued with morality. Whitehead captures this more succinctly when he writes:

... style, in its finest sense, is the last acquirement of the educated mind, it is also the most useful. It pervades the whole being. The administrator with a sense of style hates waste; the engineer with a sense for style economises his materials; the artesian with a sense of style prefers good work. Style is the ultimate morality of the mind.

With style, which is a product of professionalism, you attain your end and nothing but your end. With style the effect of activity is calculable, and foresight is the last gift of goods to man but professionalism makes this possible. With professionalism your power and value is increased, because your mind is not distracted with irrelevancies, and you are more likely to attain your object. Style is the exclusive privilege of the expert or professional. No one can ever hear about the style of an amateur painter, of the style of an amateur teacher. Style is always the product of specialist study, the peculiar contribution of specialism to culture.

Nigerian education in its present form suffers from a lack of definite aim, and from external machinery that kills its vitality. Nigerian education is yet to consider either to produce amateurs or experts (professionals). The profound change in the world which the $21^{\text {st }}$ century has produced is that the growth of knowledge has given foresight. The amateur is essentially a man with appreciation and with immense versatility in mastering a given routine. But he lacks the foresight that comes from special or professional knowledge. The object of this paper is to suggest how to produce the professional imbued with morality without loss of essential virtues of the amateur. The machinery of our secondary education is rigid where it should be yielding and lacks where it should be rigid.

\section{Conclusion}

We have been able to $\mathrm{x}$-ray the role of education in social reconstruction and development. It is discovered that 
education is an impetus for development but education without morality and professionalism can only serve as tools for self promotion. But education with morality and professionalism can effectively engineer social reconstruction and promote development effortlessly. This is the position of this paper.

\section{References}

Agulana, C. (2009). "Ethics and Education" in Philosophy and Education: An Introductory Text for Nigerian Undergraduate, A. F. Uduigwomen and K. Ogbinaka (Eds.). Calabar: Jochrisam, Pp 73-81.

Booth, W. C. and Gregory, M. W. (1988). The Harper and Row Reader Liberal Education Through Reading and Writing, New York: Harper and Row Publishers.

Brown, B. (2008). "Professionalism in Education" A paper presented at a Workshop for Teachers in Odukpani Local Government Area, organized by Education Authority.

Ekanem, S. A. (2005). "A Philosophy of Education for Technological Development in Nigeria." Unpublished Ph.D. Dissertation, University of Calabar, Nigeria.

Oladipo, O. (2009). Philosophy and Social Reconstruction in Africa, Ibadan: Hope Publication Ltd.

Omoregbe, J. I. (2000). Ethics, A Systematic and Historical Study. Lagos: Joja Educational Research and Publishers Ltd.

Oshita, O. O. (2009). "Philosophy of Education and National Development" in Philosophy and Education: An Introductory Text for Nigerian Undergraduate (A. F. Uduigwomen and K. Ogbinaka (Eds). Calabar: Jochrisam Publishers.

Ovat, B. S. (2002). Ethical Revival in Nigeria. Lagos: Gogaps Production and Services Ltd.

Ozumba, G. O. (2010). Philosophy and Method of Integrative Humanism. Calabar: Jochrisam Publishers.

Whitehead, N. (1929). The Aim of Education and other Essays. Oxford: Oxford University Press. 
